Received: 3 July 2019

Revision received: 17 October 2019

Copyright $\odot 2019$ ESTP

Accepted: 21 October 2019

www.estp.com.tr

DOI 10.12738/estp.2019.4.004 • October $2019 \cdot 19(4) \cdot 48-64$

Article

\title{
Statistical Analysis of Students' Behavioral and Attendance Habits in Engineering Education
}

\author{
Vanessa Ibáñez \\ Universidad Católica de València \\ "San Vicente Martir", Spain \\ Josep Silva \\ Universitat Politècnica de València, Spain
}

\author{
Sergio Pérez \\ Universitat Politècnica de València, Spain \\ Salvador Tamarit \\ Universitat Politècnica de València, Spain
}

\begin{abstract}
This study aims at quantifying the relationship between the marks of students and their seating position in the classroom. The study is cross-sectional, quantitative, observational, and correlational. It analyzed data collected throughout two academic years about the students' marks (in different terms, courses, and degrees) and about their daily seating position (so, every change was recorded) for both theory and practice lessons. The quantitative data collected in the study was statistically analyzed. The main result is that the seating position is significantly correlated with the marks in the studied context (engineering schools with classrooms with 5-66 students). Other side results show a positive influence on marks of working alone with respect to sharing the computer with a classmate; indicate where do students who give up the course usually sit, and when in the academic term do, they give up. This article provides empirical data with regards to the relation between classroom seating and academic performance in engineering schools. The results obtained quantify this relation, but they cannot determine whether it is causal, consequential, or both. This study complements other studies that correlated motivation with seating preferences.
\end{abstract}

\section{Keywords}

Classroom seating $\bullet$ learning $\bullet$ evaluation $\bullet$ classroom $\bullet$ marks

*This work has been partially supported by MINECO/AEI/FEDER (EU), under grant TIN2016-76843-C4-1-R; and Generalitat Valenciana, under grant PROMETEO-II/2015/013 (SmartLogic).

Correspondence to Sergio Pérez, PhD, Departamento de Sistemas Informáticos y Computación. Camino de Vera, s/n, E-46022 - Valencia, Spain. Email: serperu@dsic.upv.es.

Citation: Ibáñez, V., Pérez, S., Silva, J., \& Tamarit, S. (2019). Statistical analysis of students' behavioral and attendance habits in engineering education. Educational Sciences: Theory and Practice, 19(4), 48 - 64. http://dx.doi.org/10.12738/estp.2019.4.004 
It is a common belief that the back rows (or also those seats near the exit door) of a classroom are often occupied by those students less interactive or less interested in the subject, while front rows are occupied by the best students (Kregenow, Roger, \& Price 2011; Marshall \& Losonczy-Marshall, 2010; Zomorodian et al., 2012). This study aims at quantifying the relation between seating position and marks in the context of engineering education. In particular, this work studies whether there exists a correlation between the seats chosen by students and their marks, and it quantifies this relation (e.g., the average difference between the marks of the back rows and front-rows students). Additionally, the collected data is used to perform other complementary analyses related to attendance habits.

\section{State-of-the-Art}

Traditionally, students choose where they sit, and this election has been often ignored even in active learning methodologies. This is surprising because there exist several studies that strongly correlate the seating position of a student with his final mark (Miura \& Sugihara, 2011; Vander Schee, 2011). Most of these studies were done in schools for primary or secondary education (e.g., Benedict \& Hoag, 2004; Chandran, 2015; Fernandes, Huang, \& Rinaldo, 2011; Kausar, 2019; Perkins \& Wieman, 2005; Szparagowski, 2014; Tagliacollo, Volpato, \& Junior, 2010; Wannarka \& Ruhl, 2008), but there also exist several studies done in a higher education context, and they produced similar results (see e.g., Parker, Hoopes, \& Eggett, 2011; Rennels \& Chaudhari, 1988; Shernoff et al., 2016; Shimada et al., 2018; Silva, 2010).

The importance of the seating position and its relationship with the academic performance has been studied from different perspectives. For instance, some recent studies stablished a relation between attention and "flexible seating" (Rollo, Smith, \& Prapavessis, 2017; Rollo, Crutchlow, Nagpal, Sui, \& Prapavessis, 2019), also known as "dynamic seating" (Burgeson, 2017), and, which comprehends alternative seating devices and configurations (e.g., standing desks, stability balls, therapy cushions, cycling desks). Those studies measure the difference between dynamic seating and traditional seating, concluding that there exists a relationship between physical activity and student attention, and claiming that the integration of dynamic seating in the classroom may be an attractive alternative to traditional seating options with benefits for increasing attention among students.

Traditional seating has been largely studied for decades. For instance, Giles, Johnson, Knight, Zammett, and Weinman (1982) concluded that the student's level of immediate recall is directly associated with their location in the classroom. The learning advantages of seating in the front rows of the lecture hall have already been studied in education psychology (Cuseo, Thompson, Campagna, \& Fecas, 2016): better view of the projection screen and blackboard, clearer hearing of the professor's speech, higher degree of attentiveness due to fewer (or absence) of other students between them and the professor, and increased eye contact with the professor, making the student feel more responsible to pay attention and take notes.

The relation between the students' marks and their seating position is not necessarily consequential. It may well be causal. The seating position may reflect the student's motivation, which does influence the selection of the seat (D'souza, 2018). There exist, however, studies where students' positions were selected by the teacher, and the results concluded that students scored $68.1 \%, 71.6 \%$, and $80 \%$ on the course exams

when seating on the back, middle, and front rows, respectively (Rennels \& Chaudhari, 1988). These results indicate that better marks are not directly related to the selection of the sit (the selection was random), but they are related to the learning benefits of sitting in the front and center rows.

Clearly, there are different student personalities (D'souza, 2018). Some students are afraid of being asked or they are just shy. This makes them sit at the end of the classroom to avoid the teacher's questions. 
On the other hand, other students sit far from the teacher to talk with other students (for instance, if they are not interested in the lesson or if they cannot follow the teacher's explanation). This is also common for students that get distracted easily and cannot keep their attention for long time periods. Other students, however, tend to sit in the front rows to avoid being distracted by the noise of their classmates and to follow the lesson (Cuseo et al., 2016).

The relationship itself between seat locations and marks is dependent on the specific context of the lectures. This was already noted by another university study (Kalinowski \& Toper, 2007), which identified influencing factors such as the size of the lecture room, the academic year (they suggest that students in the last years are more motivated and thus the relation is weaker for them), and the duration of the lecture (if the lecture is long, the relation is stronger because it is more difficult for students in the back rows to keep the attention for long periods of time). For this reason, the results found in this study must be contextualized to engineering lectures with 5-66 students and classrooms of 4 to 7 rows. The correlations identified may vary if the kind of student or size of classrooms changes.

\section{Contributions}

This study collected data throughout two academic years at two engineering schools. The statistical analysis of the data correlates student's seating position (considering lecture rooms and laboratories) with their marks. This study proposes a new way of measuring the relation between the seats and the academic performance, which basically consists on associating the marks to the chairs (ignoring the identity of the students that were sitting on them). There exist other studies that provide similar results, some of them applied on primary and secondary schools (Çinar, 2010; Montello, 1988), while others consider university education (Meeks et al., 2013; Navarro Jover \& Martínez Ramírez, 2018; Silva, 2009b; Silva, 2010). Unfortunately, most of these studies used a small sample of students. Additionally, the collected data is used in other complementary analyses to answer the following questions: Do the students who regularly attend to class get better marks? Do students who sit alone get better marks than those who sit in pairs? When do students give up the courses and where do these students sit? Do the best students sit together? And the less diligent ones?

\section{Method}

\section{Participants}

In the research participated 255 students of $24.2 \pm 3.6$ years old (range 20-49), 232 male and 23 females, from the Engineering Design and Computer Science Schools, both at the Universitat Politècnica de València (Spain). The participants were all students of 8 different subjects in 5 different degrees: 48 in Computer Science Engineering Master's degree, 74 in Industrial Design Engineering Bachelor degree, 5 in Software Engineering, Formal Methods, and Information Systems Master degree, 62 in Computer Engineering Bachelor degree, and 66 in the Associate Degree in Computer Engineering.

\section{Instruments}

Before starting this research, we implemented a software system called Attendance Registration Tool (Tool-ART). This software was installed on all computers in all classrooms. Tool-ART is free, open source, and publicly available at http://www.dsic.upv.es/ jsilva/seatsandmarks/. The purpose of Tool-ART was to perform online exams as well as automatically collect and process attendance data. Every session, the tool recorded the position (row and column) of all students when they logged in. In classrooms without 
computers, the position of each student was manually recorded by the teachers. The collection of this data was done in the same way as attendance is registered: at some point in the lecture, usually when students were doing an exercise, the professor registered in a paper with the names of all students the row and column where they were seated.

All this information was collected for both lectures and practical (laboratory) lessons, and because they are made in different classrooms, each pair (group-classroom) was recorded separately. Besides, for each course, the results of the official examinations were included in the study. Each course has one or two final examinations (one in the middle and one at the end) and both of them were registered.

\section{Procedure}

This study is cross-sectional, quantitative, observational, and correlational. The research was conducted in compliance with World Medical Association (WMA) Declaration of Helsinki - Ethical Principles for Medical Research Involving Human Subjects, 2013.

Tool-ART generated several reports with the information about marks and seating positions (Figures 1, 2, and 3 were generated by Tool-ART). This raw information was aggregated to calculate more complex statistics. A major challenge was to obtain results associated with the individual physical seats inside the classroom (instead of the commonly used results associated with individual students). Bearing this in mind, we defined a novel approach (we have not found other studies in any educational context that analyzed the data in the way we did). In this study, instead of focusing on students, each single chair was associated with a mark, which was calculated from all the data collected from the (possibly different) students that sat on that chair. Later, the data were combined to calculate aggregated results. The information provided by Tool-ART is summarized hereunder.

Average mark of a chair. This statistic indicates the average mark obtained in an exam by one chair. To obtain this value, the marks of all students that sat in that chair along the course (if a student sat several times in the same chair, his mark was counted several times) were added up and divided by the number of times the chair was used (therefore, this value represents the average mark of a single occupation of one seat). Examples of this fact can be seen in Figure 1, where every chair is labelled with its mark.

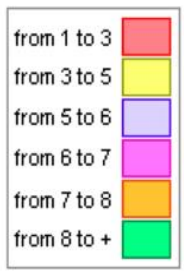

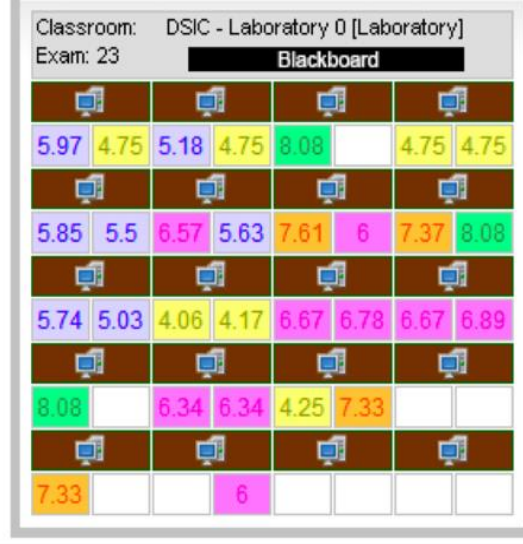

(a) Course PRG - Group: Practicals PL1
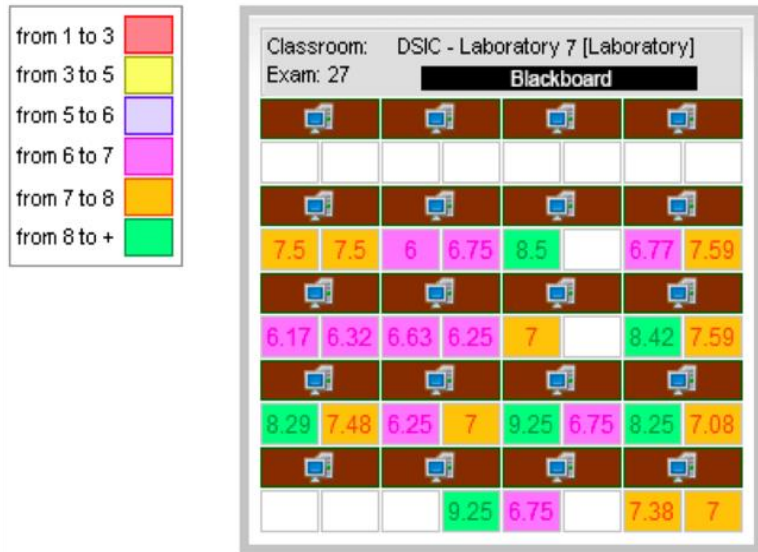

(b) Course GUI - Group: Practicals PL5

Figure 1. Two (real) examples of average marks of chairs in a group 
Note that computers are shared by two students. The blank chairs were never occupied by any student in any session. Lecture halls and labs have a symmetric and proportional distribution of chairs, thus, row $2 \mathrm{i}$ is twice as far to the professor as it is row $\mathrm{i}$. The reader should not extract conclusions from these figures, because they just show unprocessed data from two examples of courses.

Occupancy of a chair. This statistic represents the number of times a chair was occupied along the course (by the same student or different ones). Figure 2 provides examples of these counters.

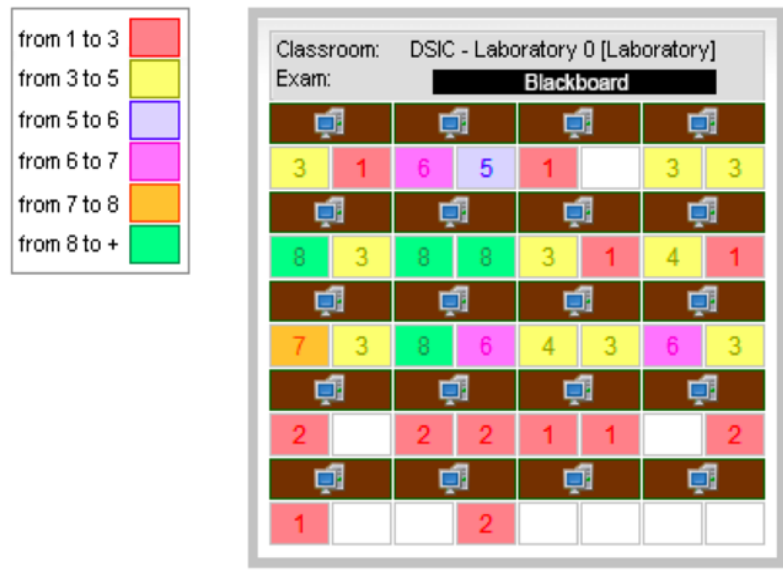

(a) Course PRG - Group: Practicals PL1
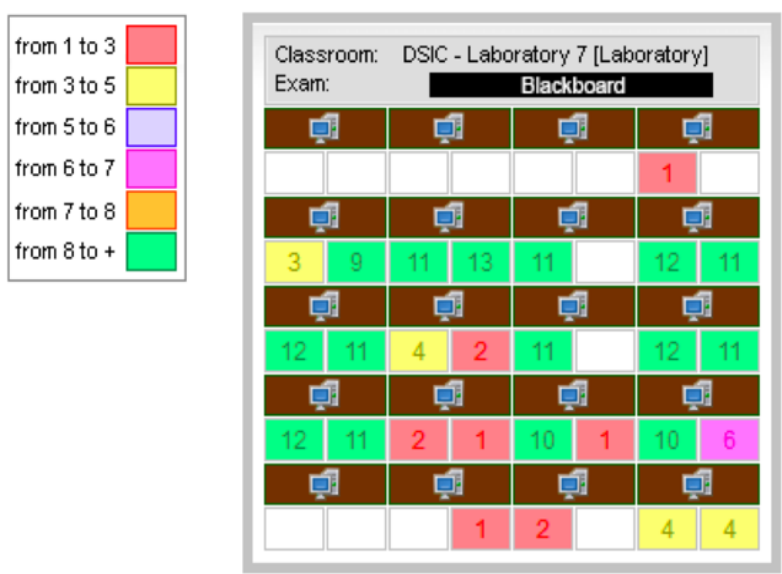

(b) Course GUI - Group: Practicals PL5

Figure 2. Two (real) examples of number of times each chair has been occupied

Occupancy of a chair by students who gave up the course. This statistic indicates the number of times a student who did not take the exam sat in a chair. Some examples are shown in Figure 3.
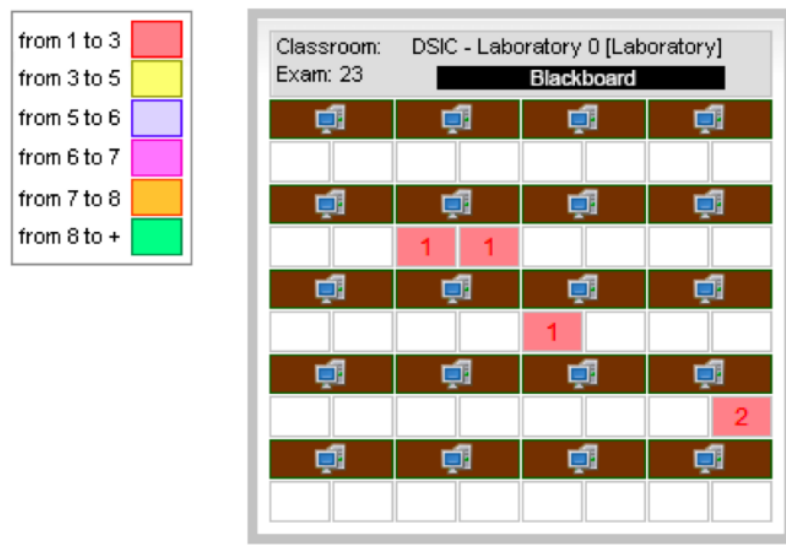

(a) Course PRG - Group: Practicals PL1
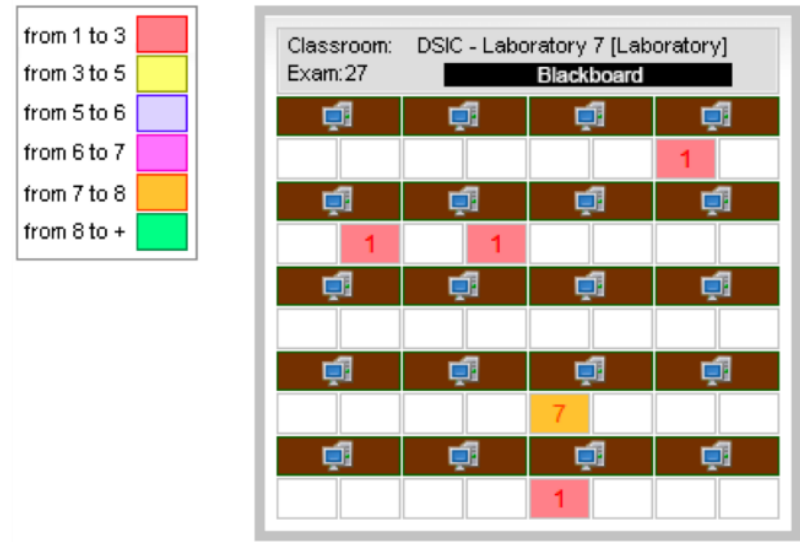

(b) Course GUI - Group: Practicals PL5

Figure 3. Two (real) examples of number of uses of chairs by students who did not take the exam 


\section{Data Analysis}

All the information collected by Tool-ART was processed with statistical analyses to produce aggregated results that combine different groups and classrooms. In all cases, 95\% symmetric confidence intervals were computed. Lectures and laboratory lessons stand for different working environments, at lectures the interaction with the teacher is mainly receptive, while at the laboratory, almost all work is performed in an autonomous way. For this reason, the groups were divided into theory and practice groups. The data were analyzed in a two-phase process. The first phase was used to obtain individual results per group. Then, a second phase was run to combine all the data obtained for all groups, producing global results.

Phase 1: All data collected by Tool-ART were processed with R. For each group, the mean of the whole group and the mean for each row of the classroom were obtained. After that, the normalized average mark, which shows the average mark of the row with respect to the average mark of the group, was calculated. Finally, a statistic called attendance, which represents how many times the chairs in each row were used (only students that took the exam were considered in order to obtain this value), was derived from the collected data.

Phase 2: Firstly, the information of all groups was divided into two sets: theory and practice groups. To produce statistically valid results that can be extrapolated, a second process of normalization was introduced because the data obtained from different groups cannot be mixed. There are three fundamental reasons that justifies the normalization process. (i) The scale used to mark must be the same (e.g., 10-point scale), so that a mark of 8 points means the same in all groups. Therefore, all marks were scaled in the interval [0-10]. (ii) The average of marks from different groups cannot be combined or computed properly if these groups have different average marks. For instance, a mark of 6 points can be a bad (far below the mean) mark in a group with an average mark of 9 points, and it can be a good mark in one group with an average mark of 5 points. In order to combine marks from different groups, the marks of each group were normalized with respect to the average mark of the group. (iii) The confidence level of the marks associated with different chairs may differ. In order to compare data with different confidence levels, the computed marks consider the number of attendances associated with each mark.

After the normalization process, the data of all groups could be properly combined. The normalized average mark was calculated for theory and practice lessons. Also, the number of attendances in a specific row divided by the number of attendances in all rows (represented as a percentage) was derived. In the analysis, those rows with a percentage of attendances lower than $5 \%$ were considered non-representative and were discarded.

After obtaining all these initial indicators, a statistical analysis was conducted with a sample consisting on more than 1300 attendances obtained for different professors, students, courses, groups, classrooms, exams, degrees, terms, and academic years. The size of the sample was big enough, and the data were heterogeneous enough, to at least, detect indicators not affected by small differences in the subsamples.

A statistical analysis was carried out for the two defined sets (theory and practice). For each set, data were analyzed with the Mantel test based on Pearson product-moment correlation (999 replicates were used) in the first place. Afterwards, to complement this test an analysis of variance (ANOVA) was performed. Finally, the ANOVA was augmented with the Tukey HSD post-hoc test to further analyze the differences between the rows inside the classroom. All those analyses were performed using R.

Further statistical analyses. After having studied the relation between the students' marks and their seating position, the data was transformed and prepared for other statistical analyses. Different 
statistical procedures were carried out to measure different aspects of students' behavior and their impact on marks: the sitting preferences of students, the subpopulation of those students that give up the course, the differences observed between students sitting alone or in pairs, and the impact on marks of regular attending. These studies are described in the following subsections.

Do the best students sit together? And the less diligent ones? First, the difference in absolute value of the marks obtained in the different exams by students who sat in adjacent chairs was analyzed. This analysis considered the number of times they sat together. The Mantel test was performed in order to study the relation between the number of times two students sit together and their marks.

When do students give up the courses and where do these students sit? First, a student who gives up the course should be understood as a (enrolled) student who finally does not take the final exam. The sample considered to perform this analysis was formed by those students who attended the class at least once, and that gave up the course without taking the final exam.

On the one hand, to analyze when do students give up the course, the number of students in the sample that attended to each session was counted. This determined whether a similar number of attendances were registered all days, or if, contrarily, the distribution was not uniform and indicative of some tendency. The study has been also carried out by splitting the data in four-month and annual courses in order to analyze whether the length of courses has some influence on the student's giving up. On the other hand, the seats of those students who gave up de course were analyzed by counting the number of times that the students who did not take the final exam sat in a certain position of the classroom. The study of these seats was carried out separately for lectures and practicals.

Do students who sit alone get better marks than those who sit in pairs? To answer this question, the information was handled in a very specific way. Firstly, the difference between sitting in pairs in the laboratory and in lectures must be explained. In the laboratory, it was considered that two students seated in pairs if and only if they shared the same computer. In contrast, in the lecture hall, it was considered that two students seated in pairs if they seated together. In both cases the students were free to choose where to sit in each session, and the amount of work to do was the same (e.g., in a lab session, they had to solve the same 20 exercises either by themselves or with their classmate). The number of times a student sat in pairs or alone was recorded for every student. Then, some of the students were eliminated from the sample because they attended, e.g., half of the year alone, and the other half in pairs. In particular, a threshold of 75\% was defined to filter out the students: students were classified as "attending alone" (respectively "attending in pairs") if they attended alone (respectively in pairs) to at least $75 \%$ of the sessions. Then, the analysis compared the average mark of those students attending alone and attending in pairs with respect to the average mark.

Do the students who regularly attend to class get better marks? To answer this question, for each course, the number of times each student attended to class was recorded. This number was divided by the total number of sessions taught along the year, producing what we call the rank of attendance. It was considered that those students with a rank of attendance below $20 \%$ do not regularly attended to class. Therefore, students were classified into two categories: students who do not regularly attend to class and students that regularly attend to class (rank of attendance above 20\%). To statistically measure the attendance-mark relation, a binomial regression (logistic regression) was calculated with all the collected data. 


\section{Results}

The null hypothesis of the study was the students' marks and their seating positions in the classroom are unrelated. In order to validate or invalidate this hypothesis, Tool-ART collected a sample of 2160 attendances. All collected and processed data, and the performed analyses are publicly available at: http://www.dsic.upv.es/ jsilva/seatsandmarks/.

\section{Theory Lectures}

First of all, the result of properly combining the data of all theory groups as described in the data analysis section is shown in Table 1.

Table 1. Normalised average marks and attendance for lectures

\begin{tabular}{ccc}
\hline Row & Attendances & Normalised average mark \\
\hline 1 & $127(19.75 \%)$ & 1.16 \\
2 & $163(25.35 \%)$ & 1.05 \\
3 & $218(33.90 \%)$ & 0.88 \\
4 & $135(21.00 \%)$ & 0.99 \\
\hline
\end{tabular}

The rows in the table represent the rows in the classroom (e.g., row three in the table represents row three in the classroom). This table show the information of the normalized average mark of the data over all the data collected. It shows that the mark of a student seated in the first row of the classroom is on average $16 \%$ higher than the mean.

Figure 4 (top left) shows a standard box plot with the distribution of data, where quartile Q1, Q2 (median), and Q3 are depicted for each row. The white point at the bottom of row 1 represents an outlier. The result of the Mantel test obtained a $p$-value of .07 . Therefore, the null hypothesis might be rejected. Thus, an ANOVA was performed, and it produced a significant result $\left(F_{(3)}=8.35, p=1.89 \mathrm{e}-05\right)$.

Note that the significance probability value $(\operatorname{Pr}(>F)=1.89 \mathrm{e}-05)$ is three orders of magnitude below the significance level. Therefore, considering a significance level of .05 , the null hypothesis can be rejected. This provides an important result: the position of students in the lecture hall and their marks are correlated. The row-mark relation supporting this result is depicted in Figure 4 (top right). The result is shown in the plot of Figure 4 (bottom). Recall that those lines not crossing the zero value represent significant differences. Therefore, this plot proves that rows (r3-r1), (r4-r1), (r3-r2) have a statistically different relation with the mark. In all cases, the closer the student is to the blackboard and the professor, the better his mark is.

\section{Practicals}

The same analysis was done for practicals. As can be deduced from Table 2, the students in the first row of the laboratory obtained a mark on average $14 \%$ higher than the mean.

Table 2. Normalised average marks and attendance for practicals

\begin{tabular}{ccc}
\hline Row & Attendances & Normalised average mark \\
\hline 1 & $108(16.80 \%)$ & 1.14 \\
2 & $226(35.15 \%)$ & 0.97 \\
3 & $230(35.77 \%)$ & 0.96 \\
4 & $106(16.49 \%)$ & 1.06 \\
5 & $51(7.93 \%)$ & 0.99 \\
\hline
\end{tabular}



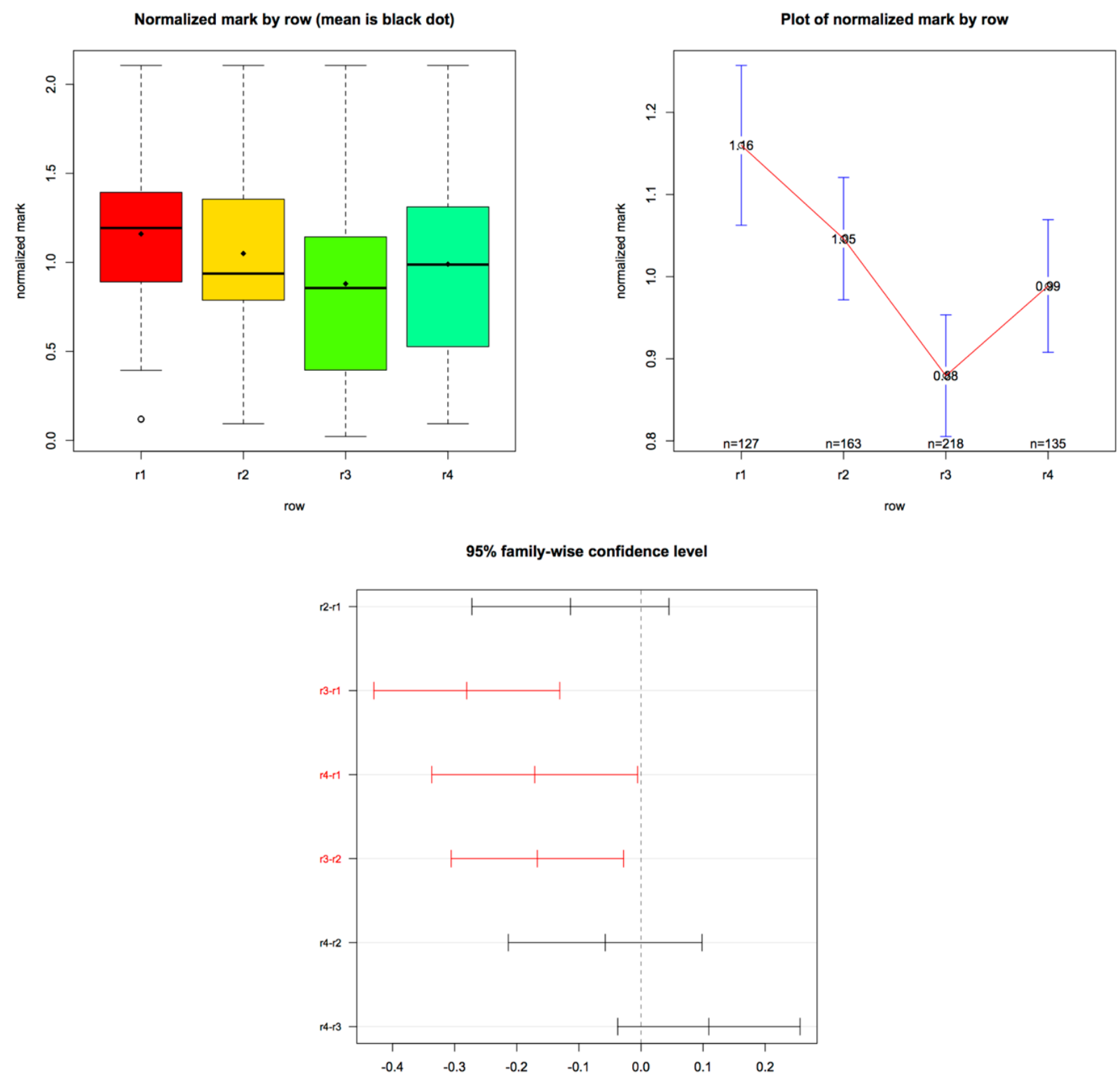

Figure 4. Charts with results about the position-mark relation (theory groups)

Figure 5 (top left) shows the standard box plot with the data distribution. The result of the Mantel test produced a $p$-value of .01, which, again, indicated that the null hypothesis might be rejected also for practicals. Then, the ANOVA obtained a significant value $F_{(4)}=12.57, p=6.9 \mathrm{e}-10$. The value $\operatorname{Pr}(>F)$ $=6.9 \mathrm{e}-10$ indicates that, also in practicals, students' marks are correlated with their position in the laboratory. The row-mark relation can be observed in the plot of Figure 5 (top right). The plot in Figure 5 (bottom) shows the result of the Tukey HSD post-hoc test. This plot indicates that those students seated in row r1 got higher marks than those in r2, r3, and r5. Similarly, those seated in row r4 got higher marks than those in rows $\mathrm{r} 2$ and $\mathrm{r} 3$. 

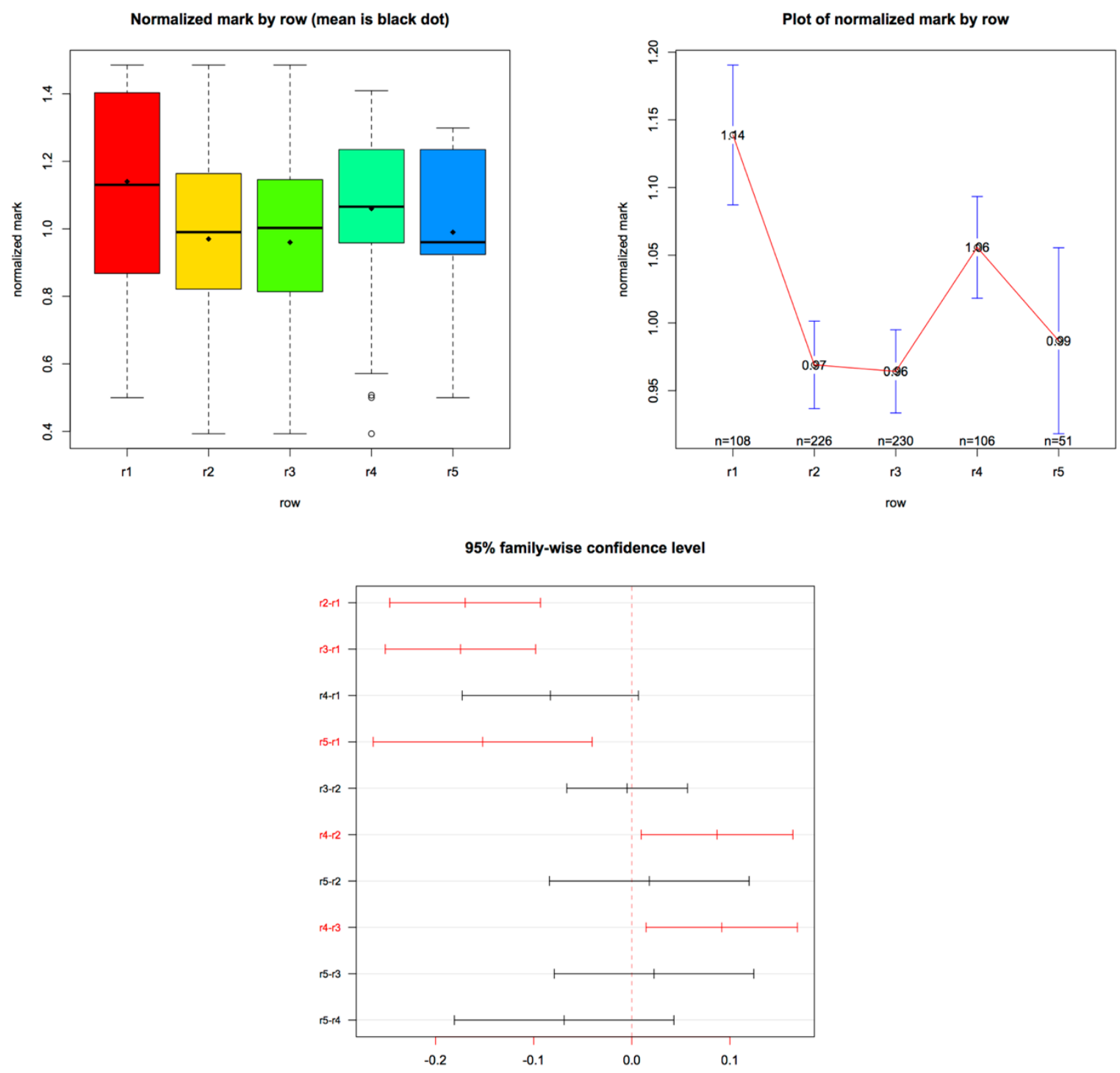

Figure 5. Charts with results about the position-mark relation (practice groups)

\section{Further Statistical Analyses}

Do the best students sit together? And the less diligent ones? The difference in absolute value of the marks by students who sat in adjacent chairs is summarized in Figure 6. Those students who formed steady pairs (14 times or more throughout the year) ${ }^{1}$ got marks with a difference in absolute value lower than one tenth. This chart shows that the more times two students sit together, more similar their marks are.

On the one hand, considering lecture groups, the Pearson Product Moment Correlation obtained was .16 , which shows a low positive relation. This means that the relation exists, but other factors must have influence on it.

\footnotetext{
${ }^{1}$ In this study, an academic term is composed of a total of 28 sessions, divided into 14 working weeks (two sessions per week).
} 


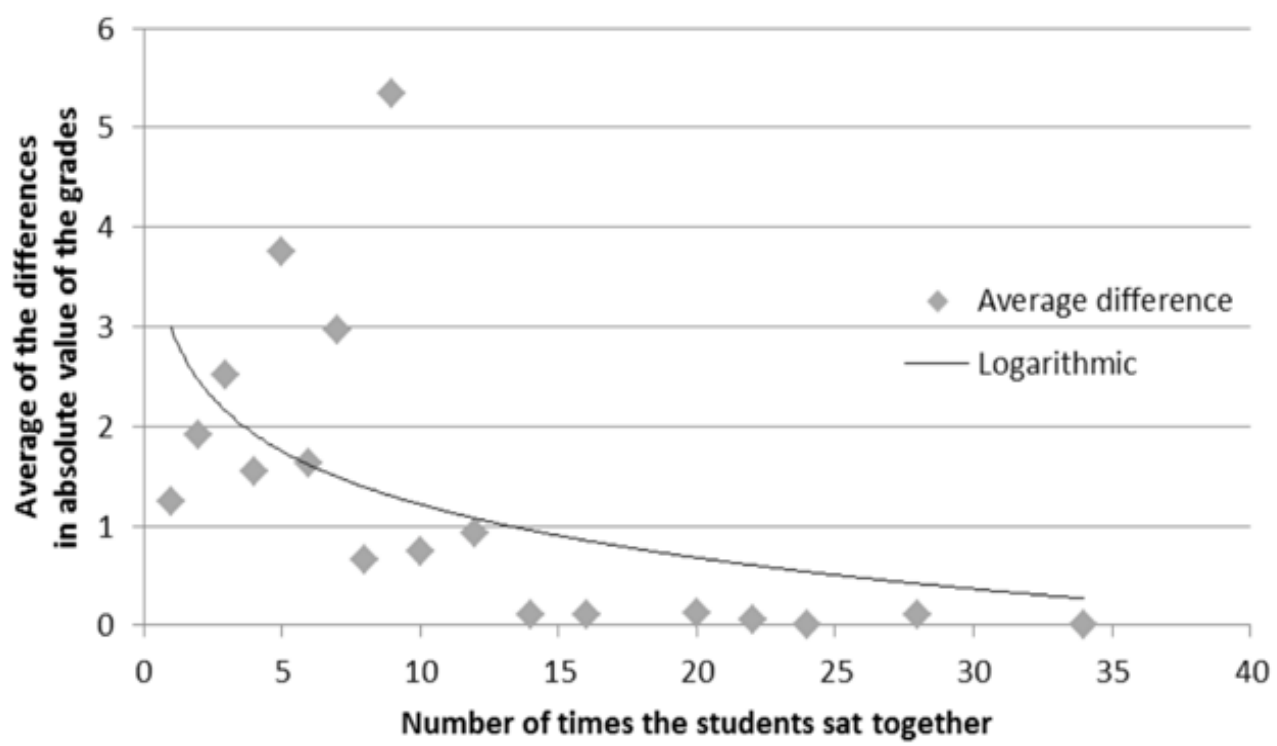

Figure 6. Relationship between difference in marks and the number of times the students sat together

On the other hand, considering practice groups, the Pearson Product Moment Correlation obtained was .34, which is significantly higher. This is a quantified evidence that the influence of a classmate (who is sharing the computer with you) in the lab is much higher than their influence in the lectures.

When do students give up the courses and where do these students sit? According to the general sample, considering all the courses and groups, it was extracted a sample of 33 students that gave up the course considering the criterion defined in the data analysis section. A chart collecting all the information about the daily attendance of these 33 students is shown in Figure 7.

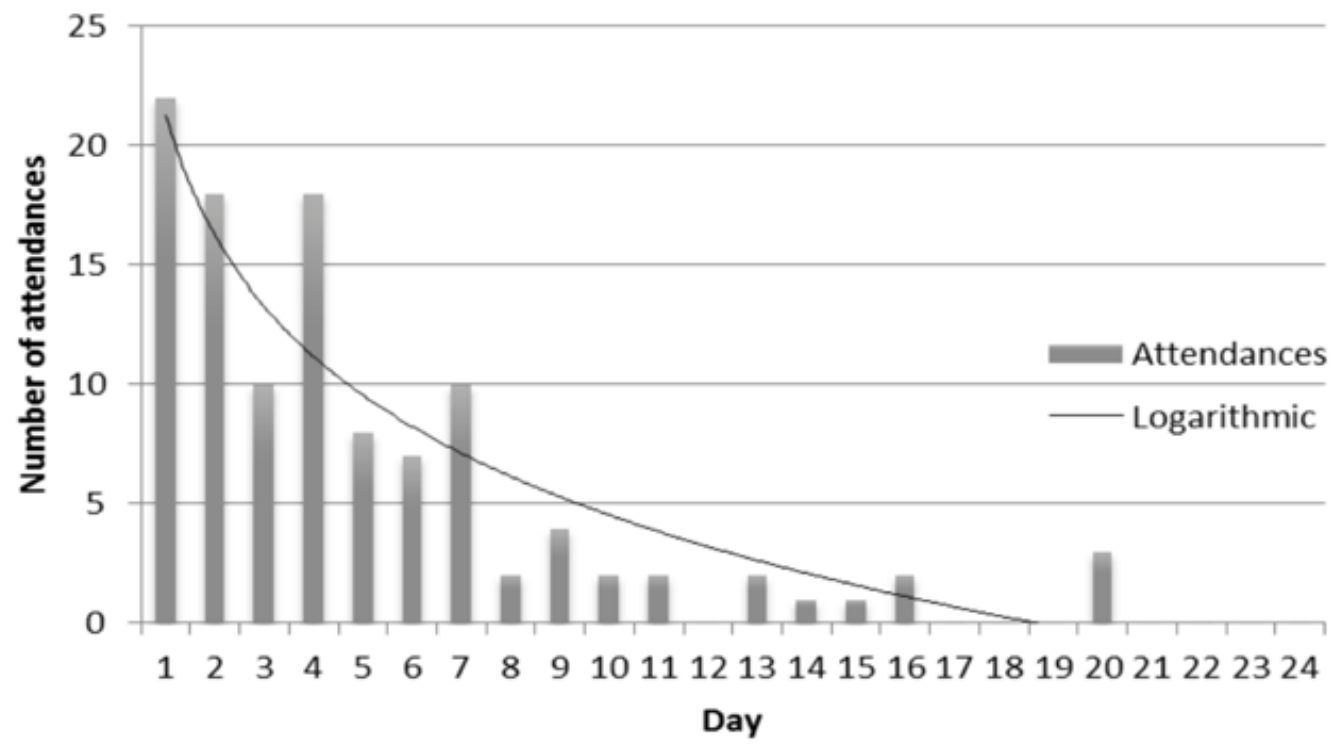

Figure 7. Attendance of students who give up the course (22 students who gave up the course attended day 1) 
Figure 7 shows a decreasing tendency of the attendance until it reaches the absenteeism at the end of the year. This tendency clearly indicates the gradual withdrawal from the course as the year moves forward. As an indicator, teachers can expect an exodus from the first third of the year. The results for fourmonth and annual courses were very similar, while it is true that withdrawal appears a little later in the annual courses.

Derived from the distribution of the data, a mathematical formula that describes the attendance of students who give up the course was extracted. For a course of $N$ sessions, the number of attendances of these students at session $1 \leq n \leq N$ is computed with the mathematical expression:

$$
\log \left(\frac{N}{n}\right) / \sum_{i=1}^{i=N} \log \left(\frac{N}{i}\right)
$$

This formula was validated with a Pearson's Chi-square test, which produced a $p$-value of .31 . This shows that the distribution of data is logarithmic and proved the formula as a confident model to predict the attendance of those students that give up.

With respect to where do these 33 students sit, Table 3 shows the results organized by rows of chairs in both lectures and practicals. Statistically it can be concluded that students who give up the course usually prefer to sit in the back rows, in both lectures and practicals.

Table 3. Total attendance results for lectures and practicals

\begin{tabular}{|c|c|c|c|c|}
\hline & Row & $\begin{array}{l}\text { Giving Up Students } \\
\text { Attendances }\end{array}$ & Total Attendances & $\begin{array}{c}\text { \% of Giving up students' attendances over } \\
\text { total attendances }\end{array}$ \\
\hline \multirow{4}{*}{$\frac{\overrightarrow{0}}{\stackrel{0}{E}}$} & 1 & $6(9.38 \%)$ & $226(21.56 \%)$ & $2.65 \%$ \\
\hline & 2 & $11(17.19 \%)$ & $281(26.81 \%)$ & $3.91 \%$ \\
\hline & 3 & $37(57.81 \%)$ & $316(30.16 \%)$ & $11.71 \%$ \\
\hline & 4 & $10(15.63 \%)$ & $225(21.47 \%)$ & $4.44 \%$ \\
\hline \multirow{5}{*}{ 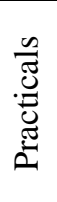 } & 1 & $8(5.48 \%)$ & $108(13.50 \%)$ & $7.41 \%$ \\
\hline & 2 & $21(14.38 \%)$ & $242(30.25 \%)$ & $8.68 \%$ \\
\hline & 3 & $37(25.34 \%)$ & $244(30.50 \%)$ & $15.16 \%$ \\
\hline & 4 & $43(29.45 \%)$ & $134(16.75 \%)$ & $32.09 \%$ \\
\hline & 5 & $37(25.34 \%)$ & $72(9 \%)$ & $51.39 \%$ \\
\hline
\end{tabular}

Do students who sit alone get better marks than those who sit in pairs? According to the criteria defined in the data analysis section, Table 4 shows the average results obtained when analyzing the influence that being alone or in pairs has over the students' marks.

Table 4. Variation of marks with respect to the average depending on whether the student sits alone or in pairs

\begin{tabular}{cccc}
\hline & Lectures & Practicals & Global \\
\hline Alone & $+14.56 \%$ & $+5.35 \%$ & $+8.43 \%$ \\
In Pairs & $-2.20 \%$ & $-5.96 \%$ & $-3.67 \%$ \\
\hline
\end{tabular}

As can be seen in the last column, those students who seated alone got, in general, $12.10 \%$ higher marks than those seated in pairs. Indeed, the results of the study suggest that sitting in pairs negatively influences the students' marks. This fact is even more evident in lectures, where the difference between those students that seated alone and those that seated in pairs was $16.76 \%$. 
Do the students who regularly attend to class get better marks? Figure 8 contains dispersion charts that illustrate the correlation found between the rank of attendance and the students' marks for both lectures (Figure 8a) and practicals (Figure 8b). Those students who did not regularly attend to class got a mark lower than the average (26.17\% lower) and those students that did regularly attend to class got a mark higher than the average (13.43\% higher). Therefore, the difference between the marks of those students who did not regularly attend to class and those who attended regularly is almost $41 \%$.

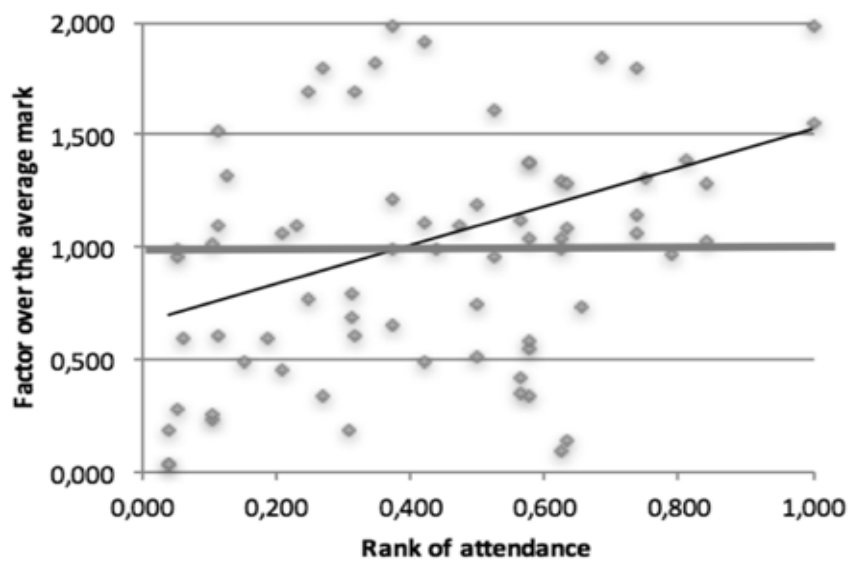

(a) Relationship between attendance and marks in lectures

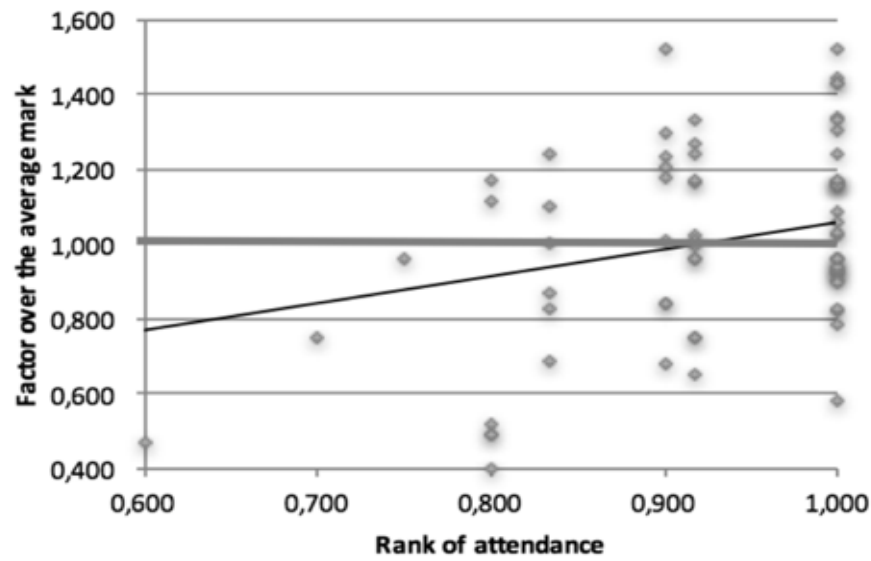

(b) Relationship between attendance and marks in practicals

\section{Figure 8. Relationship between the rank of attendance and marks}

There is a big dispersion in the charts, which means that the variance is high, probably because there are many other factors influencing the marks. In lectures - where the professor has an important role-, all students that attended more than $80 \%$ of the lectures got a mark over the average. Thus, attending many lectures has a positive impact on the mark. But in practicals - where the professor is less important, and autonomous work (which could be also done at home) prevails - this relation is different. In practicals, it is important to attend a minimum of sessions. Those students that attended less than $80 \%$ of the practicals got a mark below the average. Thus, not attending a minimum of practical sessions has a negative impact on the mark. 
The binomial regression performed over the data produced the result $\operatorname{Pr}(>|z|)=0.03$. This is an evidence that there exists a correlation between the student's marks and their attendance to class along the course

\section{Discussion}

The results obtained are aligned with several previous studies. In particular, the significant correlation between the students' positions and their marks was also identified in a study performed in United States with over 407 university students (Shernoff et al., 2016). These results contrast, however, with those obtained in the study presented by Navarro Jover and Martínez Ramírez (2018), where they found no relation between the seating position and the academic performance. Nevertheless, the study by Navarro Jover and Martínez Ramírez (2018) was done with a smaller sample (49 students) and it only considered practice sessions, where this study has shown that the relation is weaker than in theory sessions.

The results of this study complement other studies and provide data to better understand the implications of those studies. For instance, D'souza (2018) analyzed the relation between the seating position and the motivation of the students. The study was performed over a sample of 407 students in a Secondary School and the class was divided in front benchers, middle benchers, and back benchers. The current study complements D'souza's study. While D'souza (2018) correlated the learning motivation with the chosen position this study correlates chosen position with marks. D'souza results (2018) indicated that there was a significant difference in the learning motivation of front, middle and back benchers. It is important to remark that neither D'souza's work nor this article are able to determine causality in the relations.

Kalinowski and Taper (2007) examined the contribution of classroom students' seating position to learning benefits. In that work, contrarily to the study described in this paper, the students were told where to sit and worked in assigned groups. Results of a multi-level regression showed that seating in the front row in a classroom led to a higher learning gain of 5-27\%, compared to seating in other rows that are farther away from the blackboard. Kalinowski and Taper's study is particularly interesting because they removed the motivation factor and the results are still similar (our results state that the front row has an average mark $16 \%$ higher than the mean in lectures and $14 \%$ in practicals). Another difference between Kalinowski and Taper's study and this study is that this study divides the academic performance into theory and practice, considering them independently (but in both of them, the result coincides).

Another study that has important similarities is the study by Shimada et al. (2018), where a classroom of 200 students was observed during a 14 weeks course in information science conducted at Kyushu University. Instead of considering rows of chairs, they studied 12 sectors in the classroom, considering the behavior of all the students in the same sectors as equal. In Shimada et al. (2018), different kind of learning activities (e.g., quizzes, reports, or logins) were carried out during the course. They concluded that seating sector had a strong correlation with learning activities results. Significant differences between front and back rows were noted for 9 of 12 activities. The main difference with that work is that they studied individual students, while we studied chairs.

Even though some previous works (see e.g., Benedict \& Hoag, 2004; Perkins \& Wieman, 2005; Silva, 2009a) discuss a subset of the questions studied here, the truth is that there exist few statistical analyses that provide quantitative evidence. Some exceptions are the studies presented in (Giles et al., 1982; Meeks et al., 2013; Montello, 1988; Rennels \& Chaudhari, 1988; Silva, 2009b; Silva, 2010). Contrarily, there exist several studies that have been conducted at primary and secondary schools (see e.g., CapwellBurns, 2007; Çinar, 2010; Tagliacollo et al., 2010, or more recently Szparagowski, 2014). While previous 
studies tried to directly relate seating positions with marks (Ganowsky, 2003; Rennels \& Chaudhari, 1988; Silva, 2010), or also with the immediate recall after a lecture (Giles et al., 1982), this study also considers other aspects such as the influence of classmates (e.g., with the rank of solitude) and some students' attendance habits. This produced quantitative evidence about other aspects of attendance that have been less studied (Boeren, 2017).

We believe that this study can contribute to a debate about whether we should consider the student's position in learning methodologies (Marx, Fuhrer, \& Hartig, 1999; Spennemann, Atkinson, \& Cornforth, 2007). A more accurate and realistic knowledge could help professors to identify students that need more help, or to take actions to help them by, for instance, advising where they should sit. We envisage a future where the learning process is monitored by software tools that will be able to recommend pairs of students in every subject so that they can enhance and complement their learning.

This study has generated a lot of information that can be useful for teachers, but it has also produced more questions that must be further studied. For instance, it would be useful to add other dimensions to the study such as gender or the presence (or lack) of repeaters (students) in the groups, being able to study their possibly different behavior. It would be also interesting to repeat the study in other areas (different from engineering schools) so that the results can be compared. All the information obtained in this kind of studies would be of great interest to design methodologies or recommendations to define student distributions inside classrooms and to maximize their learning (as studied in Capwell-Burns, 2007). The novel idea of grading chairs instead of people could be further exploited. In a whimsical world, students could enter a classroom and see the potential mark (with a range) for their chairs before choosing them.

This study has not considered motivational factors, and it is observational, so students were free to choose their seat. Therefore, we cannot determine whether seating position influences marks, or whether the opposite is true, or both. It just identified and quantified their correlation. Therefore, the role of other factors, especially physical and psychological, but also emotional and social, must be investigated. Another limitation of this study is that the distribution of the classroom was fixed. In all groups, the classrooms used a classical (orthogonal) configuration. Other classrooms configurations may produce different correlations, as suggested by Rands and Gansemer-Topf (2017). Therefore, this factor must be also further studied.

\section{References}

Benedict, M., \& Hoag, J. (2004). Seating location in large lectures: Are seating preferences or location related to course performance? Journal of Economic Education, 35(3), 215 - 231. https://doi.org/10.3200/JECE.35.3.215-231

Boeren, E. (2017). The methodological underdog: A review of quantitative research in the key adult education journals. Adult Education Quarterly, 68(1), 63 - 79. https://doi.org/10.1177/0741713617739347

Burgeson, S. (2017). Flexible seating influencing student engagement. (Master's thesis). Retrieved from https://nwcommons.nwciowa.edu/education_masters/74/

Capwell-Burns, A. (2007). Exploring the formation of groups: Students choose their own fate. Journal Communication Teacher, 21(3), 77 - 81. https://doi.org/10.1080/17404620701633894

Chandran, R. (2015). Mandatory class participation: Factors that influence, classroom practices and learning outcomes. Asian Journal of the Scholarship of Teaching and Learning, 5(2), 108 - 122.

Çinar, I. (2010). Classroom Geography: Who sit where in the traditional classrooms? Journal of International Social Research, 3(10), $200-212$.

Cuseo, J. B., Thompson, A., Campagna, M., \& Fecas, V. S. (2016). Thriving in college and beyond: Research-based strategies for academic success and personal development. Dubuque, IA: Kendall Hunt Publishing.

D'souza, G. A. (2018). Classroom seating position: A reflector of learning disposition. International Journal of Basic and Applied Research, 8(7), 430 - 438. 
Fernandes, A. C., Huang, J., \& Rinaldo, V. (2011). Does where a student sits really matter? The impact of seating locations on student classroom learning. International Journal of Applied Educational Studies, 10(1), 66 - 77.

Giles, R. M., Johnson, M. R., Knight, K. E., Zammett, S., \& Weinman, J. (1982). Recall of lecture information: A question of what, when and where. Medical Education, 16(5), 264 - 268. doi: 10.1111/j.1365-2923.1982. tb01262.x

Kalinowski, S., \& Toper, M. L. (2007). The effect of seat location on exam grades and student perceptions in an introductory biology class. Journal of College Science Teaching, 36(4), 54 - 57.

Kausar, F. (2019). A study of relationship between physical facilities in classroom and student's performance: A secondary level study. In M. Ahmad (Eds.), Proceedings of 17th International Conference on Statistical Science (Vol. 33, pp. 223-228). Lahore, Pakistan: ISOSS Publications

Kregenow, J. M., Rogers, M., \& Price, M. F. (2011). Is there a back of the room when the teacher is in the middle? Journal of College Science Teaching, 60(6), 45 - 51.

Marshall, P. D., \& Losonczy-Marshall, M. (2010). Classroom ecology: Relations between seating location, performance, and attendance. Psychological Reports, 107(2), 567 - 577. doi: 10.2466/11.22.PR0.107.5.567-577

Marx, A., Fuhrer, U., \& Hartig, T. (1999). Effects of classroom seating arrangements on children's question-asking. Learning Environments Research, 2(3), 249 - 263. https://doi.org/10.1023/A:1009901922191

Meeks, M., Knotts, T., James, K., Williams, F., Vassar, J., \& Wren, A. (2013). The impact of seating location and seating type on student performance. Education Sciences, 3(4), 375 - 386. https://doi.org/10.3390/educsci 3040375

Miura, M., \& Sugihara, T. (2011). Effect of student's seat location on programming course achievement. In A. König, A. Dengel, K. Hinkelmann, K. Kise, R. J. Howlett \& L. C. Jain (Eds.), Lecture Notes in Computer Science: Vol. 6883. Knowledge-Based and Intelligent Information and Engineering Systems (pp. 539-547). Berlin, Heidelberg: Springer. https://doi.org/10.1007/978-3-642-23854-3_57.

Montello, D. (1988). Classroom seating location and its effect on course achievement, participation, and attitudes. Journal of Environmental Psychology, 8(2), 149 - 157. https://doi.org/10.1016/S0272-4944(88)80005-7

Navarro Jover, J. M., \& Martínez Ramírez, J. A. (2018). Academic performance, class attendance and seating location of university students in practical lecture. Journal of Technology and Science Education, 8(4), 337 - 345. https://doi.org/10.3926/jotse.353

Parker, T., Hoopes, O., \& Eggett, D. (2011). The effect of seat location and movement or permanence on studentinitiated participation. College Teaching, 59(2), 79 - 84.

Perkins, K., \& Wieman, C. (2005). The surprising impact of seat location on student performance. The Physics Teacher, 43(1), 30 - 33. doi: 10.1119/1.1845987

Rands, M. L., \& Gansemer-Topf, A. M. (2017). The room itself is active: How classroom design impacts student engagement. Journal of Learning Spaces, 6(1), 26 - 33.

Rennels, M., \& Chaudhari, R. (1988). Eye-contact and grade distribution. Perceptual and Motor Skills, 67,627 - 632.

Rollo, S., Crutchlow, L., Nagpal, T.S., Sui, W., \& Prapavessis, H. (2019). The effects of classroom-based dynamic seating interventions on academic outcomes in youth: A systematic review. Learning Environments Research, 22, 153 - 171. https://doi.org/10.1007/s10984-018-9271-3

Rollo, S., Smith, S., \& Prapavessis, H. (2017). Do you want your students to pay more attention in class? Try dynamic seating! Journal of Ergonomics, 7, 217 - 220. doi: 10.4172/2165-7556.1000217

Shernoff, D. J., Sannella, A., Schorr, R., Sanchez-Wall, L., Ruzek, E., Sinha, S., \& Bressler, D. (2016). Separate worlds: The influence of seating location on student engagement, classroom experience, and performance in the large university lecture hall. Journal of Environmental Psychology, 49, 55 - 64. https://doi.org/10.1016/j. jenvp.2016.12.002

Shimada, A., Okubo, F., Taniguchi, Y., Ogata, H., Taniguchi, R., \& Konomi, S. (2018). Relation analysis between learning activities on digital learning system and seating area in classrooms. In K. E. Boyer \& M. Yudelson (Eds.) Proceedings of the 11th International Conference on Educational Data Mining (pp. 561-564). Buffalo, NY.

Silva, J. (2009a, September). ¿Están relacionadas las notas y las sillas? Paper presented at the meeting of the $17^{\circ}$ Congreso Universitario de Innovación Educativa en las Enseñanzas Técnicas (CUIEET), Valencia, Spain.

Silva, J. (2009b). ¿Influye en la nota de los estudiantes su posición en el aula? Paper presented at the meeting of the II Jornadas de Innovación Docente de la Universitat Politècnica de València (JIDINF'09), Valencia, Spain.

Silva, J. (2010). Are Marks Related to Chairs? In M. Montané \& J. Salazar (Eds.), Proceedings of 34th Annual Conference of the Association for Teacher Education in Europe (pp. 78-87). Brussels, Belgium: ATEE aisbl

Spennemann, D. H., Atkinson, J., \& Cornforth, D. (2007). Voting with their seats: computer laboratory design and the casual user. Behaviour \& Information Technology, 26(5), 409 - 420. 
Szparagowski, R. (2014). Effects of altering student seating position on student learning in an 8th grade mathematics classroom. Retrieved from https://scholarworks.bgsu.edu/honorsprojects/115.

Tagliacollo, V. A., Volpato, G. L., \& Junior, A. P. (2010). Association of student position in classroom and school performance. Educational Research, 1(6), 198 - 201.

Vander Schee, B. A. (2011). Marketing classroom spaces: Is it really better at the front? Marketing Education Review, 21(3), 201 - 210. https://doi.org/10.2753/MER1052-8008210301

Wannarka, R., \& Ruhl, K. (2008). Seating arrangements that promote positive academic and behavioral outcomes: A review of empirical research. Support for Learning, 23(2), 89 - 93.

Zomorodian, K., Parva, M., Ahrari, I., Tavana, S., Hemyari, C., Pakshir, K., Jafari, P., \& Sahraian, A. (2012). The effect of seating preferences of the medical students on educational achievement. Medical Education Online, 17(1). https://doi.org/10.3402/meo.v17i0.10448 